\title{
Hans Peter Lund, Aux Antres de Paros. Néoclassicisme littéraire au temps de Chateaubriand
}

\section{Michel Brix}

\section{(2) OpenEdition}

1 Journals

\section{Édition électronique}

URL : http://journals.openedition.org/studifrancesi/33368

DOI : 10.4000/studifrancesi.33368

ISSN : 2421-5856

Éditeur

Rosenberg \& Sellier

\section{Édition imprimée}

Date de publication : 1 décembre 2005

Pagination : 657-658

ISSN : 0039-2944

\section{Référence électronique}

Michel Brix, « Hans Peter Lund, Aux Antres de Paros. Néoclassicisme littéraire au temps de

Chateaubriand », Studi Francesi [En ligne], 147 (XLX | III) | 2005, mis en ligne le 30 novembre 2015, consulté le 19 avril 2021. URL : http://journals.openedition.org/studifrancesi/33368 ; DOI : https:// doi.org/10.4000/studifrancesi.33368

Ce document a été généré automatiquement le 19 avril 2021.

\section{(c) 9 (i) $\Theta$}

Studi Francesi è distribuita con Licenza Creative Commons Attribuzione - Non commerciale - Non opere derivate 4.0 Internazionale. 


\title{
Hans Peter Lund, Aux Antres de Paros. Néoclassicisme littéraire au temps de Chateaubriand
}

\author{
Michel Brix
}

\section{RÉFÉRENCE}

HANS PETER LUND, Aux Antres de Paros. Néoclassicisme littéraire au temps de Chateaubriand, Jaignes (Seine-et-Marne), La Chasse au Snark, 2004, pp. 195.

1 Hans Peter Lund a consacré le présent essai à l'examen des rapports complexes qu'entretient le romantisme français avec les doctrines néoclassiques qu'ont diffusées en Europe les ouvrages et les travaux de Winckelmann. Il est d'usage, dans les traités d'histoire littéraire, de tracer une ligne de démarcation très nette entre le romantisme et le néoclassicisme, et de considérer que le premier est l'antithèse du second. Hans Peter Lund a eu l'intuition que cette séparation était beaucoup moins nette qu'on ne le pense habituellement. On ne peut qu'abonder dans son sens, d'autant que sa démonstration est éloquente.

2 Ainsi, dans De l'Allemagne, $\mathrm{M}^{\text {me }}$ de Staël fonde le renouveau littéraire, non point en réaction contre le néoclassicisme, mais au contraire en étayant l'esthétique nouvelle sur la référence à l'idée du Beau absolu, sur les linéaments de la pensée néoplatonicienne et sur les thèses de Winckelmann. Comme le montre Lund, cette ambivalence se retrouve, en France autant qu'en Allemagne, tout au long de la première moitié du XIX ${ }^{\mathrm{e}}$ siècle. Chez les frères Schlegel, dont l'ambition était de tester «les chances et la possibilité du classique dans la modernité» (p. 11); chez Hegel, dont l'œuvre s'apparente à une relecture de Platon (voir p.44-45) et à ce titre exercera une influence capitale sur l'éclectisme cousinien, doctrine officielle de l'université française au XIX ${ }^{\mathrm{e}}$ siècle; chez Joseph Joubert, maître de Chateaubriand et auteur d'un Symposium prônant l'idée du Beau immuable (p. 24-25); chez Chateaubriand aussi, qui défend l'idée 
du Beau idéal - et la thèse que l'art consiste à l'exprimer - dans le Génie du christianisme. $\mathrm{Au}$ reste, grand admirateur de Poussin, du Lorrain de même que de Canova et Thorvaldsen, ses contemporains, Chateaubriand travailla à la promotion du néoclassicisme artistique en se faisant le commanditaire d'une statue à la mémoire de Pauline de Beaumont ainsi que d'un bas-relief et d'un buste honorant Poussin - travaux demandés dans l'ordre à Joseph-Charles Marin, à Desprez (lequel s'inspira des Bergers d'Arcadie, tableau de Poussin lui-même) et à Lemoyne (voir p. 125).

Hans Peter Lund relève aussi des "aveux» néoclassiques chez des écrivains comme Nodier ou Hugo, alors même que ce dernier sonnait avec fracas, dans Le Conservateur littéraire par exemple, le glas des classiques. L'ouvrage note enfin la permanence des idéaux néoclassiques après le «temps de Chateaubriand»: Lund cite ainsi diverses déclarations de Gautier, rappelle l'admiration que professait celui-ci vis-à-vis d'un peintre comme Ingres, met au jour les échos de l'esthétique néoclassique chez Flaubert (plusieurs lettres en attestent), chez Nerval (Les Chimères) ou encore chez Leconte de Lisle (les Poèmes antiques).

4 Les historiens du romantisme devront tenir compte de cette précieuse mise au point. Qu'on me permette cependant une légère critique. Lund pose un peu trop rapidement et systématiquement, à mon avis, une équivalence entre classicisme, ou néoclassicisme, et influence des littératures de l'Antiquité. Tous les auteurs de l'Antiquité n'étaient pas platoniciens ou pindariques. Anacréon, chez les Grecs, Virgile et Horace, chez les Latins, n'ont jamais été des apôtres de la quête du Beau idéal ou des hérauts de la mission «divine» des poètes. Ainsi, même si cela semble paradoxal, l'annexion d'un écrivain tel qu'André Chénier au courant néoclassique ne me paraît pas évidente. Le débat, en tout cas, grâce à Hans Peter Lund, est ouvert. 